\title{
Prevalence of late cutaneous reactivity to metabisulfites in patients with and without chronic eczema in Argentina
}

\author{
Ledit Ardusso $^{1 *}$, Jorge Molinas ${ }^{2}$, Victor Espirito Santo Cunha ${ }^{3}$, Tielli Magnus ${ }^{3}$, Ruppert Ludwig Hahnstadt ${ }^{3}$ \\ From 3rd WAO International Scientific Conference (WISC) 2014 \\ Rio de Janeiro, Brazil. 6-9 December 2014
}

\section{Background}

Sulfites are used as preservatives and antioxidants in the cosmetic, pharmaceutical and food industry. The prevalence of sensitization caused by sulfites in Argentina is unknown.

\section{Methods}

Twenty two participants, 14 males and 8 females (mean age 31 years old), without eczema (Group 1) and 20 patients, 3 males and 17 females (mean age 35 years old), with chronic eczema (Group 2), living in Rosario, Argentina, were patch tested (PT) with sodium metabisulfite (MBS - CAS: 7681-57-4) 1\% in petrolatum and with Brazilian Contact Standard Series (FDA Allergenic, Brazil). For the test, Finn Chambers (SmartPractice, USA) with $8 \mathrm{~mm}$ (standard series) and $12 \mathrm{~mm}$ (MBS) of diameter were used and the patch testing was performed according to the International Contact Dermatitis Research Group criteria (2 days of occlusion, readings on D2 and D4, using a score from + to +++ ). Chisquared test was used to examine whether there was a significantly statistical difference between positive reactions frequencies observed in two groups. The significance level for group differences was set at $p<0.05$. The software used for this analysis was the GraphPad Prism version 6 .

\section{Results}

Three participants (13.6\%) of Group 1 and four (20\%) of Group 2 presented positive reactions to MBS. There was no statistical difference between groups $(p=0.58)$. All participants of group 2 presented at least one positive reaction to substances of the Brazilian Contact Dermatitis Standard Series (FDA Allergenic) while no participants from Grupo 1 reacted to it. None of the patients with MBS PT (+) and/or (-) had a suspected history of symptoms elicitation after the consumption of food and/or beverages with MBS as additive.

\section{Conclusions}

We concluded that MBS $1 \%$ in petrolatum is suitable for patch test but the relevance of positive reaction to MBS $1 \%$ has to be better explained before its use in standard series.

\section{Authors' details}

${ }^{1}$ Medical Sciences University. National University of Rosario, Argentina. ${ }^{2}$ University of the Center Educational Latino Americano, Argentina. ${ }^{3}$ FDA Allergenic, Brazil.

Published: 8 April 2015

doi:10.1186/1939-4551-8-S1-A71

Cite this article as: Ardusso et al:: Prevalence of late cutaneous reactivity to metabisulfites in patients with and without chronic eczema in Argentina. World Allergy Organization Journal 2015 8(Suppl 1):A71.

${ }^{1}$ Medical Sciences University. National University of Rosario, Argentina

Full list of author information is available at the end of the article 